Research Article

\title{
Research on Surface Subsidence of Long-Span Underground Tunnel
}

\author{
Jun Yan, ${ }^{1,2}$ Xueying Liu, ${ }^{3}$ Xiaoyu Bai $\mathbb{D}^{3,4}$ Mingyi Zhang, ${ }^{3,4}$ Yujin Jiao, ${ }^{5,6}$ Desheng Jing, \\ Honghua Liu, ${ }^{1,2}$ Zhongsheng Wang, ${ }^{1,2}$ and Wen Kang ${ }^{1}$ \\ ${ }^{1}$ Qingdao Geo-Engineering Surveying Institute, Qingdao 266071, China \\ ${ }^{2}$ The Key Laboratory of Urban Geology and Underground Space Resources, \\ Shandong Provincial Bureau of Geology and Mineral Resources, Qingdao 266590, China \\ ${ }^{3}$ Department of Civil Engineering, Qingdao University of Technology, Qingdao, Shandong 266033, China \\ ${ }^{4}$ Cooperative Innovation Center of Engineering Construction and Safety, Shandong Blue Economic Zone, \\ Qingdao, Shandong 266033, China \\ ${ }^{5}$ Qingdao Shibei Binhai New Area Management Committee, Qingdao, Shandong 266000, China \\ ${ }^{6}$ Qingdao Metro Group Co., Ltd., Qingdao, Shandong 266033, China
}

Correspondence should be addressed to Xiaoyu Bai; baixiaoyu538@163.com

Received 11 November 2020; Revised 27 April 2021; Accepted 8 May 2021; Published 25 May 2021

Academic Editor: Valeria Vignali

Copyright (C) 2021 Jun Yan et al. This is an open access article distributed under the Creative Commons Attribution License, which permits unrestricted use, distribution, and reproduction in any medium, provided the original work is properly cited.

\begin{abstract}
In the process of urban rail transit construction, underground excavation method is often used in subway station construction. Based on a large number of measured data of Qingdao Metro Line 3, this paper analyzes and studies the ground subsidence law of long-span shallow buried excavation station. The research results show that vertical surface settlement will be caused by the excavation of both sides of the guide hole, but the settlement is relatively small, basically within $-10 \mathrm{~mm}$. Large surface settlement will occur during the middle or middle guide hole excavation, with a large settlement up to $-30 \mathrm{~mm}$. Through data fitting, it is found that the regression analysis using cubic polynomial of one degree can get better fitting effect. The horizontal surface variation rules of underground excavation stations are affected by the tunnel depth, geological conditions, management level of monitoring units, monitoring layout and monitoring accuracy, and so on. The differences in horizontal surface deformation and settlement between stations are large. Wannianquan Road Station basically conforms to the deformation law of ground settlement trough in Peck, and Junfeng Road Station directly above belongs to the whole subsidence type. This study has accumulated a large number of surface settlement monitoring data, which can provide a certain reference for the subsequent design of similar lines.
\end{abstract}

\section{Introduction}

In order to solve the increasingly prominent contradictions and promote the sustainable and healthy development of cities, the development of urban underground space has become the preferred direction of urban construction $[1,2]$, among which the construction of urban rail transit has become the main choice [3]. However, most urban rail transit projects are located underground, and the excavation of tunnels has replaced the dense space filled with stratum material with approximately circular cavities. In the construction process, the surrounding strata will inevitably be disturbed, which will destroy the original equilibrium state and cause the subsidence of the strata and the surface [4-6]. If the settlement deformation is uniform, it will have little impact on roads, pipelines, and surrounding buildings. However, settlement deformation caused by tunnel excavation is often uneven, and when the uneven settlement goes beyond a certain range, a series of problems will occur [7-9].

At present, scholars at home and abroad have conducted a large number of studies on the surface settlement deformation caused by tunnel excavation and formed several more mature methods, including empirical formula method, numerical simulation method, stochastic medium theory, and statistical analysis method. Ibrahim and Ocak [10] measured the surface settlement of parallel tunnels using 
Earth pressure balance machines (EPBM) shields in clay and sand and obtained the interaction of the double tunnel surface and the relationship between the shield parameters and the surface settlement. Yan et al. [11] elaborated on the distribution law of rockburst in Jinping secondary tunnel, studied the mechanism of rockburst prevention measures, and compared two different pressure relief blasting designs. $\mathrm{Ou}$ et al. [12] studied the surface settlement characteristics caused by a single tunnel and a double tunnel based on two sections and obtained the surface settlement caused by a single tunnel in a normal distribution. Zhang et al. [13] analyzed the field measurement data and concluded that the arch cover construction process is more suitable for largespan tunnel excavation in the "soft on the top and hard on the bottom" stratum. If construction control measures are in place, the total surface settlement can be effectively reduced, and it is recommended that the left and right pilot tunnels should be kept at 2.5 times the tunnel diameter. Meng et al. [14] used the Peck method and random medium theory to compare and analyze the ground settlement characteristics caused by the construction of large-span shallow tunnels based on field measured data.

The above studies are mostly based on numerical simulation methods. The current research on the surface settlement and deformation of large-span tunnels is relatively limited, and the conclusions drawn by the research are also quite different. The conclusions drawn by methods such as numerical simulation and random medium theory do not reflect the actual surface settlement changes well. Therefore, it is very important to use statistical analysis methods based on a large number of measured monitoring data to analyze the surface settlement and deformation laws of large-span underground tunnels. This can provide reference and guidance for the study of surface subsidence.

\section{Project Overview}

2.1. Design Overview. Line 3 is the first rail transit line under construction in Qingdao, with a total length of about 25 kilometers, 22 stations, and 1 depot. The line basically passes through the main urban area. Under the influence of road traffic and the surrounding environment, 7 stations are constructed by shallow buried excavation. This paper selects 2 of them for targeted research. The underground station is mainly located below the main road of the city. Due to the large road traffic flow and many surrounding structures, the tunnel construction requirements are strict. The engineering route of Qingdao Metro Line 3 is shown in Figure 1.

2.2. Engineering Geological Survey. According to the engineering geological exploration data of underground stations of Subway Line 3 (as shown in Table 1), the overlying soil of the stations is mainly artificially filled soil layer, clay layer, and weathered rock layer, while the main penetrating rock layer of the stations is mainly strong, medium, and breezed granite, granite porphyry, and partially lamprophyre. According to the engineering properties of various kinds of soil and soil, the geological conditions of each underground

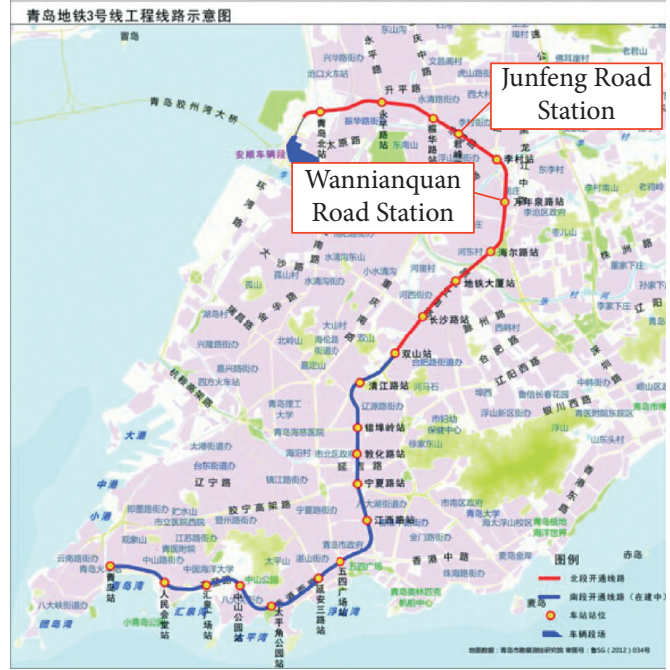

Figure 1: Qingdao Metro Line 3 project line.

excavation station have typical characteristics of "soft on the top and hard on the bottom," which are specifically manifested as soft soil above the arch, large water seepage, large disturbance of blasting and excavation, and easy instability when there is no support. The main body of the station has good geological conditions, and its rock mass is generally IIIIV grade, which needs blasting excavation and can be stabilized for a long time after excavation. Related pictures of drilling rock samples at Junfeng Road and Wannianquan Road Stations are shown in Figure 2.

The two stations studied in this paper, Wannianquan Road Station and Junfeng Road Station, have deep average burial depth and relatively good geological conditions. The arch is basically rock stratum, and the surrounding rock has strong self-stability after excavation, while the surface settlement above the tunnel is not obvious. In addition, due to the influence of geological structure, fault zones are developed in some stations. For example, Wannianquan Road Station is affected by Licun fault zone, which is mainly composed of cataclastic rocks and filled with lamprophyre and granite porphyry veins.

2.3. Overview of Hydrogeology. The groundwater in this area can be divided into quaternary pore water, weathered fissure water, and structural fissure water according to the different occurrence medium and burial conditions. Quaternary pore water mainly occurs in sand layer and is greatly affected by atmospheric precipitation. The weathered fissure water mainly occurs in the weathered rock and is distributed in the relatively low-lying terrain in a layer-like manner. It is replenished by atmospheric precipitation and overlying pore water. The tectonic fissure water mainly occurs in the tectonic belt on both sides of the fault zone and in the later intrusive dike. It is mainly replenished by atmospheric precipitation and weathered fissure water, and the local water volume is relatively large. According to the comprehensive evaluation of the construction process and geological exploration data, the overall hydrogeological 
TABLE 1: Underground excavation station main Earth and rock excavation classification and tunnel surrounding rock classification.

\begin{tabular}{|c|c|c|c|c|c|c|}
\hline $\begin{array}{l}\text { Soil (rock) } \\
\text { layer } \\
\text { number }\end{array}$ & Geotechnical name & $\begin{array}{l}\text { Main engineering } \\
\text { geological features }\end{array}$ & $\begin{array}{c}\text { Stable condition after } \\
\text { excavation }\end{array}$ & $\begin{array}{c}\text { Dredge } \\
\text { classification of } \\
\text { Earth and stone }\end{array}$ & $\begin{array}{l}\text { Surrounding } \\
\text { rock } \\
\text { classification }\end{array}$ & $\begin{array}{c}\text { Saturated } \\
\text { uniaxial } \\
\text { ultimate } \\
\text { compressive } \\
\text { strength }(\mathrm{MPa})\end{array}$ \\
\hline (1), (1) 1 & Artificial fill & $\begin{array}{l}\text { The low compactness of } \\
\text { plain and mixed filled } \\
\text { soil has poor uniformity } \\
\text { of soil quality and } \\
\text { uneven water } \\
\text { permeability, and the } \\
\text { local sandy components } \\
\text { have higher water } \\
\text { permeability. }\end{array}$ & $\begin{array}{l}\text { In the case of water, } \\
\text { the excavation is prone } \\
\text { to collapse and } \\
\text { deformation, and the } \\
\text { surface subsidence is } \\
\text { usually large. }\end{array}$ & I & VI & - \\
\hline (11), (15) ${ }_{1}$ & $\begin{array}{l}\text { Silty clay; completely } \\
\text { weathered } \\
\text { lamprophyre }\end{array}$ & $\begin{array}{l}\text { Basically in plastic or } \\
\text { hard plastic state, } \\
\text { generally poor } \\
\text { permeability, good self- } \\
\text { stability. }\end{array}$ & $\begin{array}{l}\text { It has good self- } \\
\text { stability under the } \\
\text { condition of no water, } \\
\text { but it is easy to } \\
\text { collapse when there is } \\
\text { water, and it can } \\
\text { collapse to the ground } \\
\text { when it is shallow } \\
\text { buried. }\end{array}$ & II & VI & - \\
\hline
\end{tabular}

Generally in the hard plastic state, water permeability is better; Sandy cohesive soil, the highly weathered highly weathered (12), (16) ${ }_{\text {top }}$ (16) middle, (16) 2 , (16) 4 granite, mesozone, highly weathered granite porphyry, and sandy soil-like cataclastic rock rock has the characteristics of waterdisintegrating, which is greatly disturbed by blasting construction and has a short selfstabilizing time under the condition of no support.

The rock material is soft The surrounding rock and red in color. The is easy to collapse and weathering fissures are deformation. When developed seriously. the support is not in The water is poor, but place or there is a big the water permeable is collapse, the vault good.

Subzone of highly (16) bottom, weathered granite; (17) 4 massive cataclastic rock

The surrounding rock is prone to collapse and deformation and needs timely support in case of water.

Light red, local structural joints and weathered fissures are well developed and contain groundwater. With the development degree of fissures, there is a great difference in water abundance and permeability.

\begin{tabular}{|c|c|c|}
\hline $\begin{array}{l}\text { (18), (18) } \\
1, \\
\text { (18) } 2,(18)_{6}\end{array}$ & $\begin{array}{l}\text { Breezy granite, breezy } \\
\text { lamprophyre, breezy } \\
\text { granite porphyry, and } \\
\text { granite porphyry }\end{array}$ & $\begin{array}{l}\text { Light red, hard rock, a } \\
\text { few joints, and fissures } \\
\text { are not rich in } \\
\text { groundwater. }\end{array}$ \\
\hline
\end{tabular}
often falls.
Good self-stability and small collapse may occur when there is no support, which requires higher control of blasting construction.
IV IV

\section{Strong self-stability can be exposed for a} long time; the probability of collapse is low, but the roof with poor combination between rock strata is prone to collapse. 


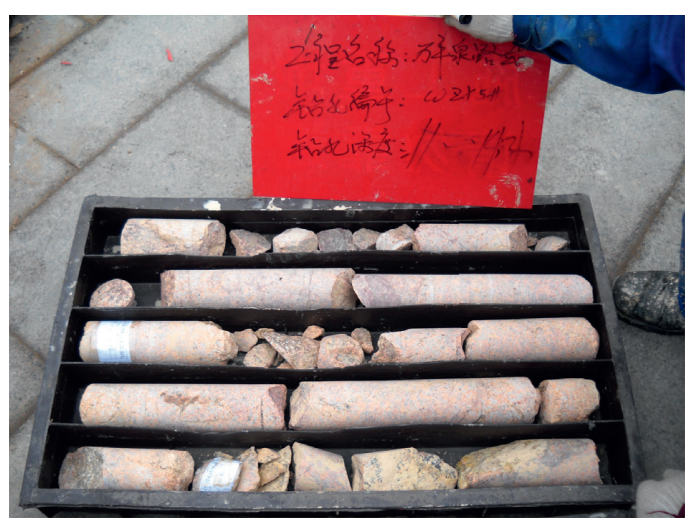

(a)

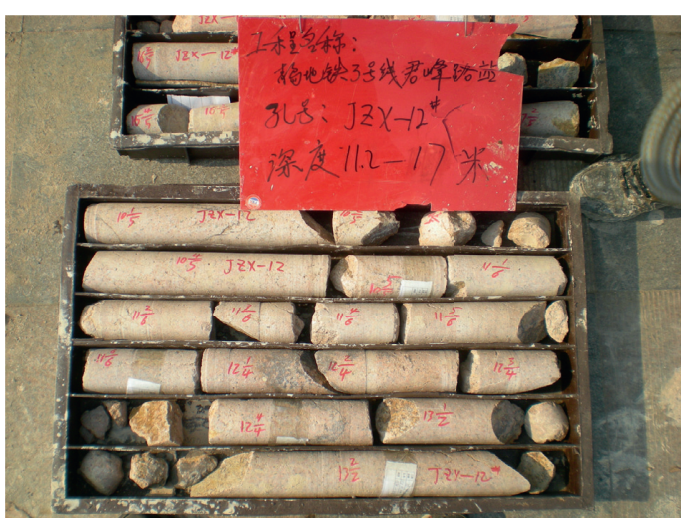

(b)

Figure 2: Rock drilling sampling diagram. (a) Wannianquan Road Station (b) Junfeng Road Station.

conditions in each station site are good, but there is still water seepage in the tunnel face and the initial branch surface after excavation. If the treatment is not timely or not in place, it is not conducive to the control of the upper stratum settlement.

\subsection{Main Construction Methods of Long-Span Underground} Tunnels. With the increasing of the excavation section size, the construction difficulty increases gradually, and the available construction methods become more limited. At present, the main excavation methods of long-span underground tunnels in China include full-section method, step method, double-wall pit guide method, CRD method, and arch cover method [15]. The specific contents of several construction methods are shown in Table 2. The selection of large-span underground tunnel construction method in this metro fully draws on the mature experience of other regions, and according to the specific characteristics of each station, each construction method is combined to give full play to the advantages of each method (as shown in Table 3).

\section{Monitoring and Data Analysis}

In accordance with the technical Specification for Urban Rail Transit Engineering Monitoring (GB50911-2013) [16], construction monitoring should be carried out throughout the construction process of urban rail transit engineering. During subway construction, the construction unit selects the monitoring unit of the construction party to monitor the main body of the tunnel and the surrounding environment according to the design requirements, and the construction unit selects the third-party monitoring unit as a supplement to the monitoring of the construction party through bidding. Surface settlement is an important monitoring item in tunnel construction. The study of surface settlement monitoring data can provide some references for the related research of long-span underground tunnel.

3.1. Monitoring Method. Most surface settlement monitoring methods adopt precision leveling measurement [17]. By selecting a fixed point and measuring its height $\mathrm{H}$ based on the standard reference point, the elevation difference between it and the foundation is calculated, and then the actual monitoring height is calculated and compared with the last measured elevation; difference $\Delta H$ is the site of the sedimentation value change, namely,

$$
\Delta H_{\mathrm{t}}(1,2)=\Delta H_{\mathrm{t} 1}-\Delta H_{\mathrm{t} 2} .
$$

3.2. Monitoring Distribution Points. Surface settlement is a necessary project in tunnel excavation and can directly reflect the change of soil above the tunnel. Because it is difficult to implement the method of direct drilling and coring on the road surface for the distribution of points and it is often subject to artificial damage, the distribution point of the surface settlement this time is mainly to directly drive the spike into the road surface as the monitoring point. The places where the local conditions are satisfied and the places with higher risks shall be cored according to the specification requirements. The monitoring points are shown in Figure 3.

The measuring points of tunnel surface settlement are arranged before the tunnel face reaches the monitoring section with a diameter of 3-5 times. The longitudinal spacing of surface settlement in the underground excavation stations is basically $10-20 \mathrm{~m}$, with a row of local encryption points of $5 \mathrm{~m}$. The distribution of monitoring points is shown in Figure 4. The transverse distance is $2-5 \mathrm{~m}$, and the middle line is encrypted. In principle, the monitoring range on both sides of the middle line should not be less than $H_{0}+B$ ( $H_{0}$ is the buried depth of the tunnel, and $B$ is the width of the tunnel). When the ground conditions are limited, it can be appropriately reduced. However, when there are controlled structures on the surface, the measuring range should be widened appropriately. However, often affected by the ground environment, the distribution points are mainly concentrated directly above the main body, and the two sides extend slightly outward.

3.3. Monitoring Data Analysis Methods. The analysis methods of monitoring data generally include statistical analysis method, finite element method, boundary element 
TABLE 2: Comparison of construction methods of shallow buried excavation.

\begin{tabular}{|c|c|c|c|c|c|}
\hline Number & Construction method & Conditions of use & $\begin{array}{l}\text { Stratum } \\
\text { subsidence }\end{array}$ & $\begin{array}{l}\text { Construction } \\
\text { period }\end{array}$ & $\begin{array}{l}\text { Construction } \\
\text { cost }\end{array}$ \\
\hline 1 & Full-section method & Good stratum, span $\leq 8 \mathrm{~m}$ & General & Shortest & Low \\
\hline 2 & Step method & Poor stratum, span $\leq 12 \mathrm{~m}$ & General & Short & Low \\
\hline 3 & $\begin{array}{l}\text { Double-wall pit guide } \\
\text { method }\end{array}$ & $\begin{array}{c}\text { Poor stratum, generally used in stations } \\
\text { with a large-span }\end{array}$ & $\begin{array}{l}\text { Comparatively } \\
\text { large }\end{array}$ & $\begin{array}{l}\text { Comparatively } \\
\text { long }\end{array}$ & High \\
\hline 4 & CRD method & Poor stratum, large-span & $\begin{array}{l}\text { Comparatively } \\
\text { large }\end{array}$ & $\begin{array}{l}\text { Comparatively } \\
\text { long }\end{array}$ & High \\
\hline 5 & CD method & Poor stratum, span $\leq 14 \mathrm{~m}$ & $\begin{array}{l}\text { Comparatively } \\
\text { large }\end{array}$ & $\begin{array}{l}\text { Comparatively } \\
\text { long }\end{array}$ & General \\
\hline
\end{tabular}

method, and reverse analysis method [18, 19]. This paper mainly uses regression analysis in the statistical analysis method to analyze the law of surface subsidence. In this paper, the regression analysis of surface subsidence data is carried out using nonlinear regression analysis.

If the relationship between two variables is not linear, then the relationship between them is called nonlinear, that is, to nonlinear regression analysis. However, the basic method to deal with nonlinear regression problems is still to transform variables into linear regression first and then to deal with them by linear regression method. The commonly used methods of nonlinear regression analysis in monitoring data processing include unary multiple equations, exponential function, logarithmic function, and hyperbolic function.

\section{Surface Settlement Law}

\subsection{Law of Longitudinal Surface Settlement}

\subsubsection{Whole-Process Surface Settlement Analysis.} According to the on-site construction process, monitoring distribution points and data change curves of each monitoring point, 2-3 monitoring sections are selected from each station, 2-6 representative measuring points of each section are selected to draw the whole-process change curve, and a total of 48 surface settlement change curves are accumulated. Figures 5 and 6 show the surface subsidence change curve of Wannianquan Road Station.

According to Figures 5 and 6 , the surface settlement change process can be divided into four stages: the first stage from the beginning to the mid-May 2012, and the phase change monitoring data of subsidence have some ups and downs, but the trend of fluctuations is not big, and the cumulative settlement is small, basic within $3-5 \mathrm{~mm}$, and the corresponding construction stage is the excavation of both sides of the pilot tunnel. The second stage is from mid-May to mid-June 2012. In this stage, the excavation of the middle guide hole in the arch and the grouting reinforcement in the arch after excavation are analyzed. The third stage is from mid-June 2012 to mid-December 2012, and the corresponding construction stage is the middle and lower part excavation. This stage reflects the large fluctuation of data, but the accumulative settlement change does not show much change. In the fourth stage, from mid-December 2012 to the end, the main structure and entrance and exit of the station were mainly performed. However, it can be seen from the change curve that there was relatively obvious subsidence in June 2013, which was analyzed as the second lining construction of the arch and the temporary support removal. The settlement variation of Wannianquan Road Station at each change stage is counted as shown in Table 4.

Figures 7 and 8 show the surface settlement change curve of Junfeng Road Station.

According to the change curves in Figures 7 and 8, the change process of surface settlement can be divided into four change stages. In the first stage, from the beginning to the late-February 2012, the change of monitoring data in this stage is stable on the whole. Some points have a certain subsidence trend, but the accumulated settlement is small, basically within $-6 \mathrm{~mm}$. Corresponding construction stages are the upper three guide holes excavation. In the second stage, from late-February 2012 to late-March 2012, there is an obvious trend of subsidence in this stage, and the accumulated settlement reaches $0-15 \mathrm{~mm}$. The corresponding construction stage is the central excavation. In the third stage, from early April 2012 to mid-July 2012, the first half of this stage is divided into Earth excavation at the front of the monitoring section, and the second half is divided into Earth excavation at the lower part of the corresponding part of the monitoring section. The accumulated settlement is basically around $-14 \mathrm{~mm}$. The fourth stage is from the mid-July 2012 to the end, when the main structure is mainly constructed. In this stage, there is a small uplift, but the overall change is not large, within $5 \mathrm{~mm}$. The settlement variation of Junfeng Road Station at each change stage is counted, as shown in Table 5.

Based on the analysis of the variation curves of the whole process of surface settlement of the above stations, although some monitoring data are carried out in advance, the overall variation rules of surface settlement in the process of station excavation are roughly consistent and have certain commonness. The excavation of both sides of the guide hole will cause surface settlement, but the general settlement is relatively small, basically within $-10 \mathrm{~mm}$. Large surface settlement will occur during the middle or middle guide hole excavation. According to the difference of geological conditions, the large settlement can reach over $-15 \mathrm{~mm}$. The accumulated surface settlement caused by the first two stages of construction can usually account for more than $70 \%$ of the total settlement. During the excavation of the lower soil and the construction of the station structure, the change of surface settlement is not obvious, and some points will still 
TABle 3: Main construction methods of underground excavation station of Subway Line 3.

\begin{tabular}{|c|c|c|c|}
\hline Number & Site name & $\begin{array}{l}\text { Arch main surrounding } \\
\text { rock grade }\end{array}$ & Construction methods \\
\hline 1 & $\begin{array}{l}\text { Wannianquan Road } \\
\text { Station }\end{array}$ & $\mathrm{IV} \sim \mathrm{V}$ & $\begin{array}{l}\text { Open excavation method, CRD method, CD method, double-wall guide } \\
\text { pit method, and step method }\end{array}$ \\
\hline 2 & Junfeng Road Station & $\mathrm{IV} \sim \mathrm{V}$ & $\begin{array}{l}\text { Open excavation method, CRD method, CD method, double-wall guide } \\
\text { pit method, and step method }\end{array}$ \\
\hline
\end{tabular}

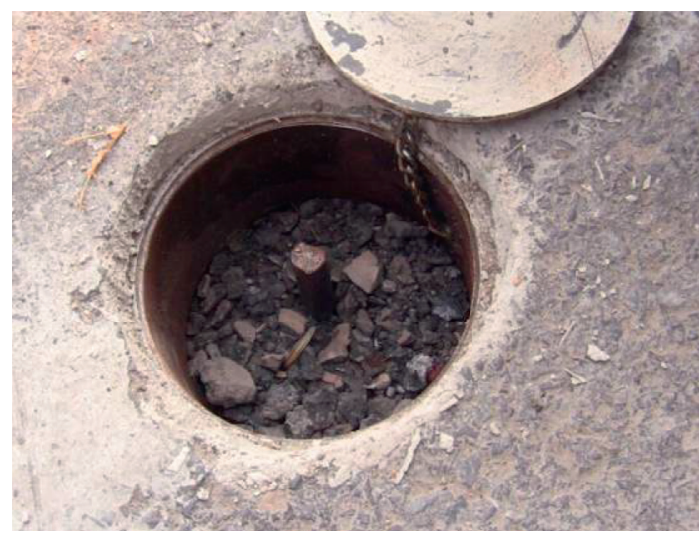

(a)

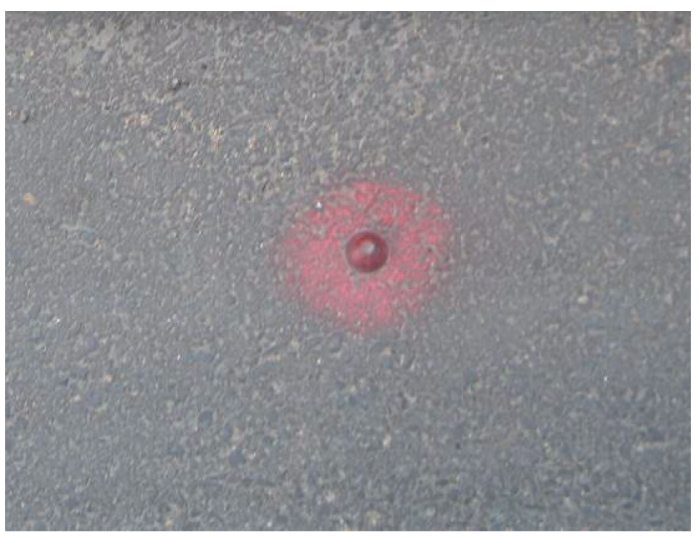

(b)

Figure 3: Surface settlement monitoring points. (a) Spike. (b) Monitoring stations.

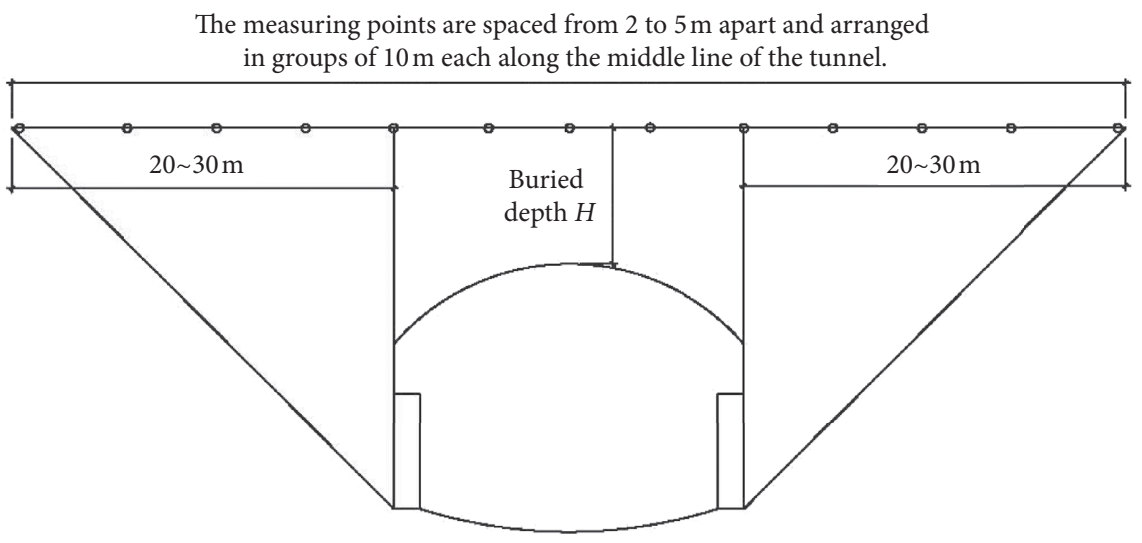

Figure 4: Design monitoring cross section.

have a certain subsidence trend due to the influence of geological conditions.

\subsubsection{Surface Settlement Curve Fitting Analysis.} According to the experience of the former construction on the subway, surrounding environment accident happens mainly in the upper body. Local collapse, pipeline leakage, excessive surface subsidence, and other accidents often occur in the excavation process of the upper part of the station yard of the pilot tunnel, so it is necessary to strengthen the construction control of the upper roadway. According to the construction experience of subway underground excavation station, tunnel collapse and surrounding environmental accidents mainly occurred in the excavation process of the guiding hole in the upper part of the main body. Local collapse, pipeline leakage, excessive ground settlement, and other accidents that occurred in the construction of underground subway stations also occurred in the excavation of the upper guide hole of the main body of the station. Therefore, it is necessary to strengthen the construction control of the upper guide hole. An in-depth analysis of surface settlement variation curves during upper or middle Earth excavation was performed, and curve fitting was performed using OriginPro software.

Based on the monitoring values of the Wannianquan Road Station (Table 6), the results of the fitting using OriginPro software are shown in Figure 9.

Its fitting formula can be obtained as $y=-1.87+0.15 x$ $-4.5 \times 10^{-3} x^{2}+4.39 \times 10^{-5} x^{3}-1.41 x^{4}$. The correlation coefficient is 0.81 , which has an acceptable correlation and the fitting effect is close to the actual change curve. 


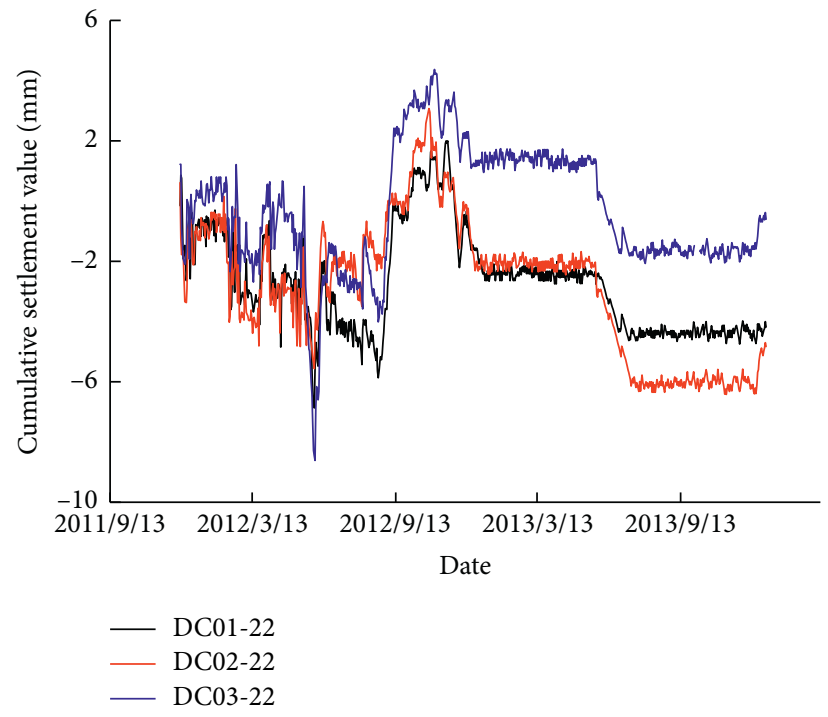

FIgURE 5: Settlement change curve of the construction company DC01-22 DC03-22 at Wannianquan Road Station.

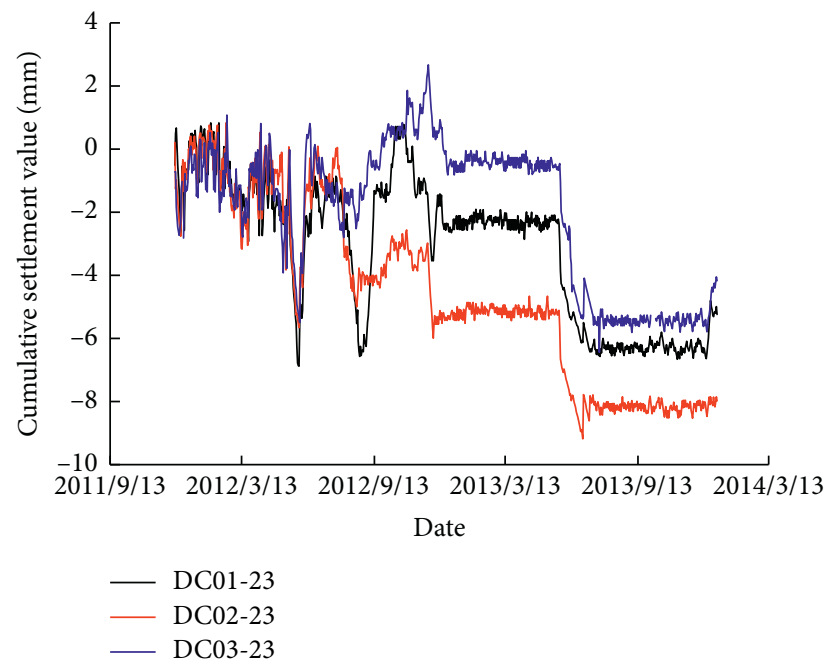

FIGURE 6: Settlement change curve of the construction company DC01-23 DC03-23 at Wannianquan Road Station.

TABLE 4: Settlement changes of the surface subsidence monitoring point of Wannianquan Road Station in different stages.

\begin{tabular}{lccr}
\hline Stages of change & Cumulative settlement value $(\mathrm{mm})$ & Cumulative change $(\mathrm{mm})$ & Proportion of total settlement $(\%)$ \\
\hline First stage & -5 & $0 \sim 5$ & 25 \\
Second stage & $-5 \sim-10$ & $0 \sim 5$ & 20 \\
Third stage & $-5 \sim-6$ & $0 \sim 0$ & 20 \\
Fourth stage & $-5 \sim-10$ & $0 \sim 8$ & 35 \\
\hline
\end{tabular}

Based on the monitoring values of the Junfeng Road Station (Table 7), the results of the fitting using OriginPro software are shown in Figure 10.

The fitting formula is obtained as $y=-0.29+0.002 x-$ $5.9 \times 10^{-4} x^{2}-1.51 \times 10^{-6} x^{3}$. The correlation coefficient reached 0.97 , showing a high correlation, and the fitting effect was close to the actual change curve.

By fitting the surface settlement deformation curve in the earthwork excavation process of each station, it is found that the fitting effect is better with the correlation coefficient basically above 0.95 . Compared with other functions, the cubic polynomial is relatively simple and fast in calculation. However, it can also be seen that the formula coefficients obtained after fitting the surface settlement change curves of each station are quite different, which indicates that the surface settlement change curve in the excavation process of long-span underground tunnel is actually greatly influenced by various factors and can only be analyzed and judged from the overall change law. 


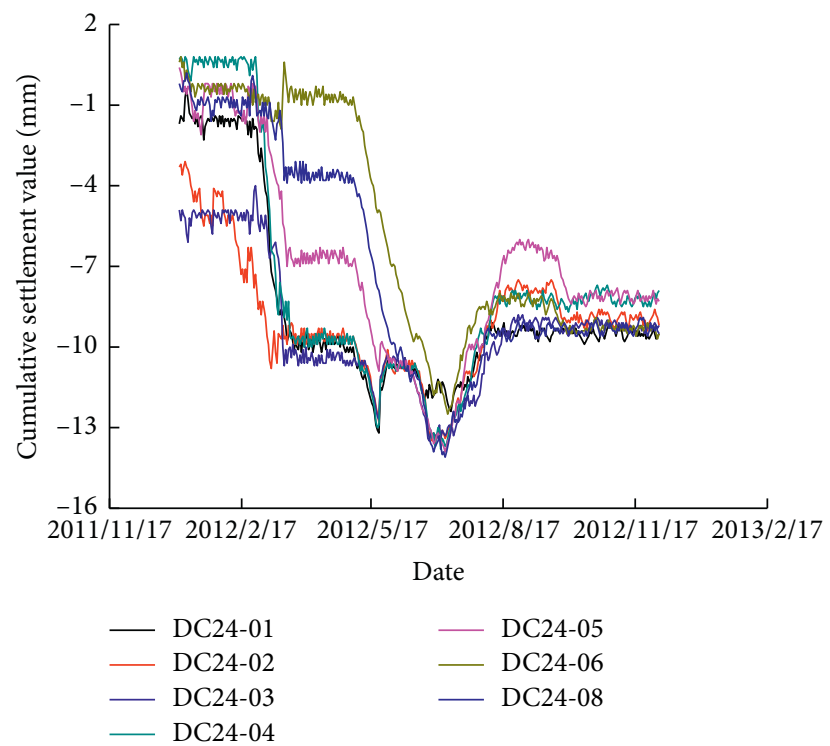

FIgURE 7: Settlement change curve of the construction company DC24 at Junfeng Road Station.

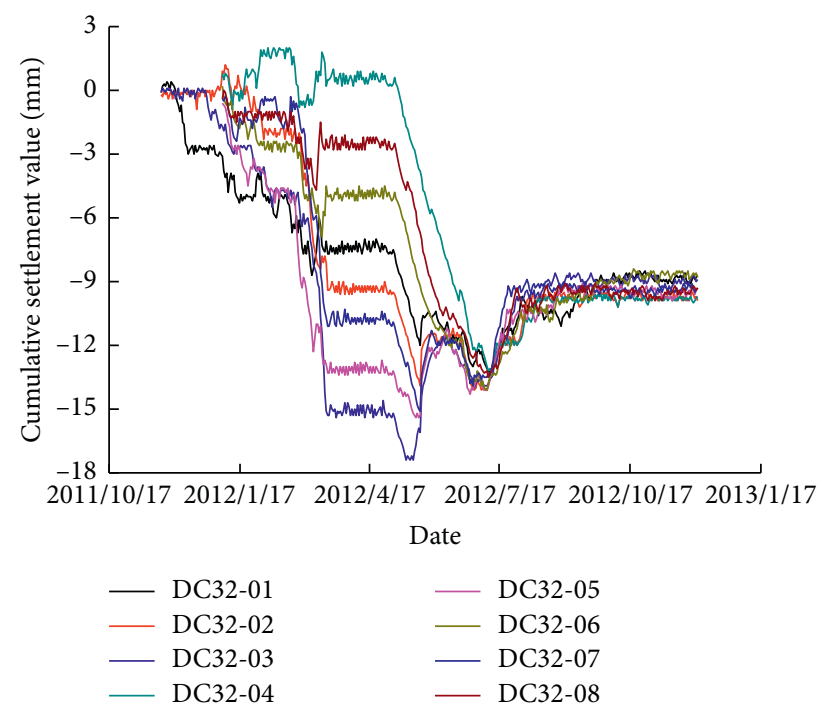

FIgURE 8: Settlement change curve of the construction company DC32 at Junfeng Road Station.

TABle 5: Settlement changes of the surface subsidence monitoring point of Junfeng Road Station in different stages.

\begin{tabular}{lccc}
\hline Stages of change & Cumulative settlement value $(\mathrm{mm})$ & Cumulative change $(\mathrm{mm})$ & Proportion of total settlement $(\%)$ \\
\hline First stage & $0 \sim-6$ & $0 \sim-6$ & 40 \\
Second stage & $0 \sim-15$ & $0 \sim 10$ & 40 \\
Third stage & $0 \sim-15$ & $3 \sim 12$ & 10 \\
Fourth stage & -10 & 5 & 10 \\
\hline
\end{tabular}

4.2. Law of Lateral Surface Settlement. The law of lateral surface settlement deformation after underground excavation of subway station is analyzed, and the settlement change of Wannianquan Road Station is shown in Table 8. According to Table 8, the lateral displacement variation curve of the section can be drawn (Figure 11).

On the whole, there are few monitoring points in Wannianquan Road Station. Each monitoring section only has one measuring point above the three guiding holes on the left, middle, and right, and there are few effective monitoring data. It can be seen from Figure 11 that the surface settlement above the station is basically larger on the center line and smaller on both sides. The cumulative settlement of measuring point 1 in monitoring section $\mathrm{C}$ is obviously larger than that of other measuring points, which is caused by long-term rolling of ground vehicles at this 
TABLE 6: Monitoring values at excavation stage of a measuring point of Wannianquan Road Station.

\begin{tabular}{|c|c|c|c|c|c|c|c|c|c|c|c|}
\hline $\begin{array}{l}\text { Time } \\
\text { (d) }\end{array}$ & $\begin{array}{l}\text { Cumulative } \\
\text { value }(\mathrm{mm})\end{array}$ & $\begin{array}{l}\text { Time } \\
\text { (d) }\end{array}$ & $\begin{array}{l}\text { Cumulative } \\
\text { value }(\mathrm{mm})\end{array}$ & $\begin{array}{c}\text { Time } \\
\text { (d) }\end{array}$ & $\begin{array}{l}\text { Cumulative } \\
\text { value }(\mathrm{mm})\end{array}$ & $\begin{array}{l}\text { Time } \\
\text { (d) }\end{array}$ & $\begin{array}{l}\text { Cumulative } \\
\text { value }(\mathrm{mm})\end{array}$ & $\begin{array}{l}\text { Time } \\
\text { (d) }\end{array}$ & $\begin{array}{l}\text { Cumulative } \\
\text { value }(\mathrm{mm})\end{array}$ & $\begin{array}{l}\text { Time } \\
\text { (d) }\end{array}$ & $\begin{array}{l}\text { Cumulative } \\
\text { value }(\mathrm{mm})\end{array}$ \\
\hline 1 & -0.65 & 31 & -0.36 & 61 & -0.87 & 91 & -1.74 & 121 & -1.35 & 151 & -1.25 \\
\hline 4 & -1.28 & 34 & -0.43 & 64 & -1.44 & 94 & -1.93 & 124 & -0.59 & 154 & -2.71 \\
\hline 7 & -0.83 & 37 & -0.08 & 67 & -1.38 & 97 & -1.71 & 127 & -0.82 & 157 & -2.42 \\
\hline 10 & -1.47 & 40 & -0.38 & 70 & -0.90 & 100 & -0.84 & 130 & -0.66 & 160 & -3.84 \\
\hline 13 & -0.68 & 43 & -0.06 & 73 & -0.88 & 103 & -0.27 & 133 & -0.68 & 163 & -5.07 \\
\hline 16 & -0.77 & 46 & -0.24 & 76 & -1.32 & 106 & -0.29 & 136 & -1.03 & & \\
\hline 19 & -0.43 & 49 & -0.04 & 79 & -1.38 & 109 & -0.85 & 139 & -0.99 & & \\
\hline 22 & -0.19 & 52 & -0.03 & 82 & -1.59 & 112 & -0.66 & 142 & -1.77 & & \\
\hline 25 & -0.18 & 55 & -0.16 & 85 & -1.61 & 115 & -0.93 & 145 & -2.01 & & \\
\hline 28 & -0.34 & 58 & -0.47 & 88 & -1.91 & 118 & -0.65 & 148 & -2.06 & & \\
\hline
\end{tabular}

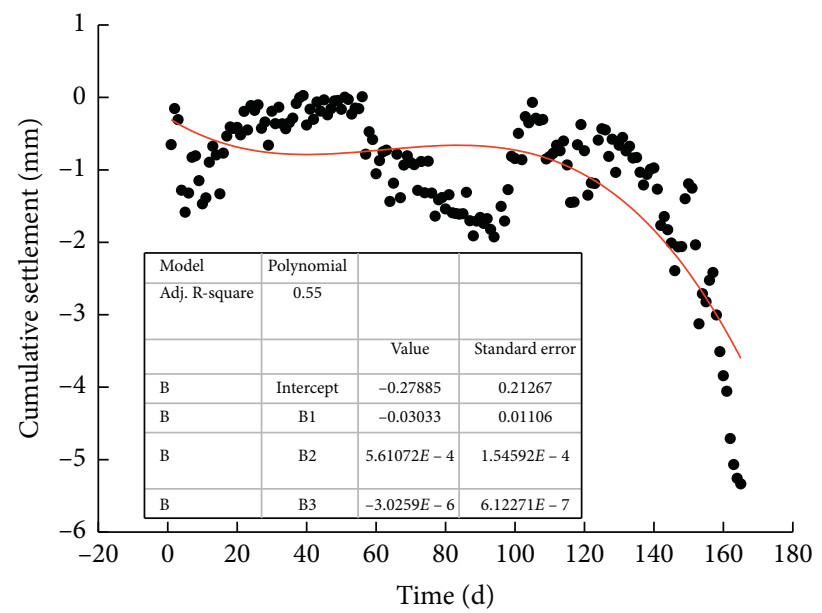

FIgURE 9: Data change curve fitting diagram.

TABLE 7: Monitoring values of a measuring point in Junfeng Road Station during excavation.

\begin{tabular}{|c|c|c|c|c|c|c|c|c|c|c|c|}
\hline $\begin{array}{l}\text { Time } \\
\text { (d) }\end{array}$ & $\begin{array}{l}\text { Cumulative } \\
\text { value }(\mathrm{mm})\end{array}$ & $\begin{array}{l}\text { Time } \\
\text { (d) }\end{array}$ & $\begin{array}{l}\text { Cumulative } \\
\text { value }(\mathrm{mm})\end{array}$ & $\begin{array}{c}\text { Time } \\
\text { (d) }\end{array}$ & $\begin{array}{l}\text { Cumulative } \\
\text { value }(\mathrm{mm})\end{array}$ & $\begin{array}{l}\text { Time } \\
(\mathrm{d})\end{array}$ & $\begin{array}{l}\text { Cumulative } \\
\text { value }(\mathrm{mm})\end{array}$ & $\begin{array}{l}\text { Time } \\
(\mathrm{d})\end{array}$ & $\begin{array}{l}\text { Cumulative } \\
\text { value }(\mathrm{mm})\end{array}$ & $\begin{array}{l}\text { Time } \\
(\mathrm{d})\end{array}$ & $\begin{array}{l}\text { Cumulative } \\
\text { value }(\mathrm{mm}) \\
\end{array}$ \\
\hline 1 & -0.13 & 41 & -1.57 & 81 & -2.33 & 121 & -7.49 & 161 & -7.89 & 201 & -11.10 \\
\hline 5 & 0.13 & 45 & -1.00 & 85 & -2.43 & 125 & -7.56 & 165 & -8.72 & 205 & -11.54 \\
\hline 9 & -0.10 & 49 & -1.51 & 89 & -2.27 & 129 & -7.60 & 169 & -9.27 & 209 & -12.44 \\
\hline 13 & -0.27 & 53 & -1.97 & 93 & -2.63 & 133 & -7.57 & 173 & -10.21 & 213 & -13.19 \\
\hline 17 & -0.50 & 57 & -1.94 & 97 & -3.95 & 137 & -7.41 & 177 & -11.03 & & \\
\hline 21 & -1.07 & 61 & -1.95 & 101 & -4.33 & 141 & -7.55 & 181 & -10.19 & & \\
\hline 25 & -1.07 & 65 & -2.04 & 105 & -5.93 & 145 & -7.53 & 185 & -10.31 & & \\
\hline 29 & -0.93 & 69 & -1.74 & 109 & -6.19 & 149 & -7.55 & 189 & -10.57 & & \\
\hline 33 & -1.00 & 73 & -2.12 & 113 & -7.17 & 153 & -7.42 & 193 & -10.64 & & \\
\hline 37 & -1.27 & 77 & -2.25 & 117 & -7.37 & 157 & -7.77 & 197 & -10.90 & & \\
\hline
\end{tabular}

point. This is similar to the settlement of Zhanshan Road Station monitored at the same time, which is large on both sides and small in the middle.

The settlement changes of Junfeng Road Station are shown in Table 9. The lateral displacement variation curve of the monitored section is shown in Figure 12.

According to the lateral displacement variation curve of Junfeng Road Station (Figure 12), the monitoring data of all monitoring sections in this station are basically consistent, the lateral displacement trough is not obvious, and the immediate upper part of the station is basically the overall settlement, but the cumulative settlement value is generally small, less than $10.00 \mathrm{~mm}$, which is consistent with the thick depth of the tunnel and good geological conditions.

Based on the analysis of the changes of the surface lateral displacement in the above stations, it can be seen that the overall variation of the surface lateral displacement deformation in the long-span underground excavation stations is quite different due to the influences of tunnel depth, geological conditions, management level of monitoring units, 


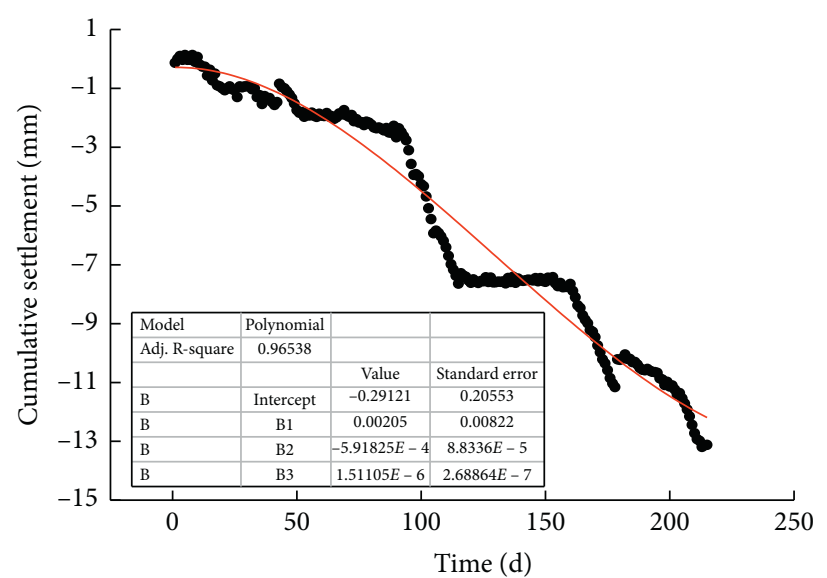

Figure 10: Data change curve fitting diagram.

TABLE 8: Change of lateral displacement of a monitoring section in Wannianquan Road Station.

\begin{tabular}{lccc}
\hline Test group & A & B & C \\
\hline & -1.33 & -2.34 & -23.26 \\
Accumulated settlement value after excavation $(\mathrm{mm})$ & -1.12 & -5.39 & -17.51 \\
& 2.21 & 0.88 & -1.86 \\
\hline
\end{tabular}

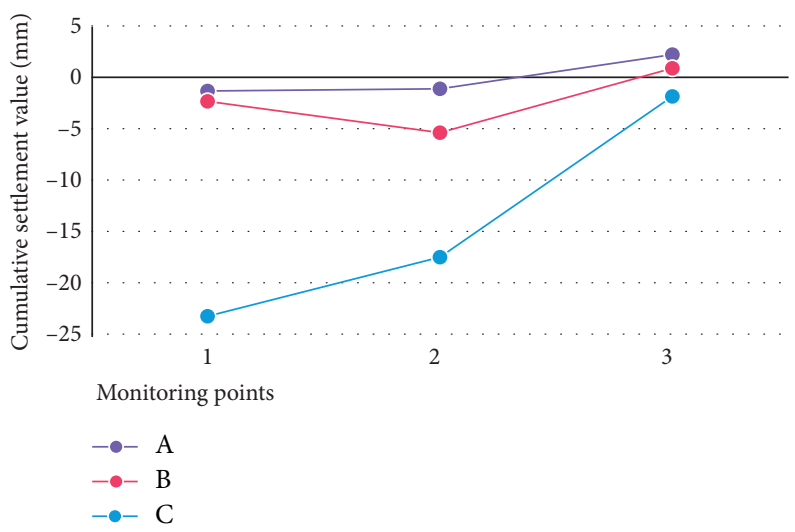

FIGURE 11: Variation curve of lateral displacement of monitored sections at Wannianquan Road Station.

monitoring layout and monitoring accuracy, and so on. However, it can also be simply seen that the lateral surface settlement of Wannianquan Road Station basically conforms to the surface settlement trough of Peck. The surface settlement of Junfeng Road Station is an overall settlement, and there is no obvious difference in the corresponding area directly above the station. Therefore, the impact on the pipelines and roads above the station can be considered to be small, and only the final settlement needs to be controlled.

4.3. Analysis of Surface Settlement Control Standards. In recent years, the control standard of surface subsidence caused by urban subway tunnel excavation has been a hot research topic. The surface settlement caused by tunnel excavation is affected by geological conditions, tunnel burial depth, construction method, support parameters, and other factors, so it is difficult to accurately describe the changing process and final deformation value of the surface settlement. However, through a large number of engineering practices and scientific studies [20-22], the surface settlement deformation caused by tunnel excavation can be followed regularly. Through statistical analysis of a large number of measured data, a more reasonable standard value of surface settlement control can be found to guide other line tunnel excavations.

Data selection should first ensure the consistency of data and basically conform to the actual construction process onsite. According to the previous construction experience, the total settlement amount between the end of excavation and the end of construction is generally small, and the impact on 
TABle 9: Variation of lateral displacement of a monitored section in Junfeng Road Station.

\begin{tabular}{|c|c|c|c|c|c|c|c|c|c|}
\hline Test group & DC07 & DC08 & DC09 & DC11 & DC13 & DC18 & DC20 & DC22 & DC30 \\
\hline \multirow{8}{*}{ Accumulated settlement value after excavation $(\mathrm{mm})$} & -9.34 & - & -9.44 & -9.58 & -9.44 & -9.78 & -9.56 & -9.18 & - \\
\hline & -9.18 & - & -8.40 & -9.28 & -9.52 & -9.70 & -9.78 & -9.00 & -9.46 \\
\hline & -9.50 & -8.72 & -9.28 & -9.02 & -7.74 & -9.24 & -8.86 & -9.68 & -9.28 \\
\hline & -8.26 & -9.66 & -9.08 & -8.88 & -9.68 & -9.72 & -8.76 & -9.20 & -9.28 \\
\hline & -9.34 & -9.22 & -9.02 & -8.68 & -9.64 & -8.18 & -9.52 & -7.36 & -9.40 \\
\hline & -8.70 & -9.00 & -8.52 & -8.94 & -9.44 & -8.66 & -8.38 & -8.60 & -8.98 \\
\hline & -9.46 & -9.08 & -9.18 & -9.28 & -9.32 & -9.24 & -9.44 & -8.72 & -9.62 \\
\hline & - & - & - & - & -9.32 & - & -8.50 & -8.78 & - \\
\hline
\end{tabular}

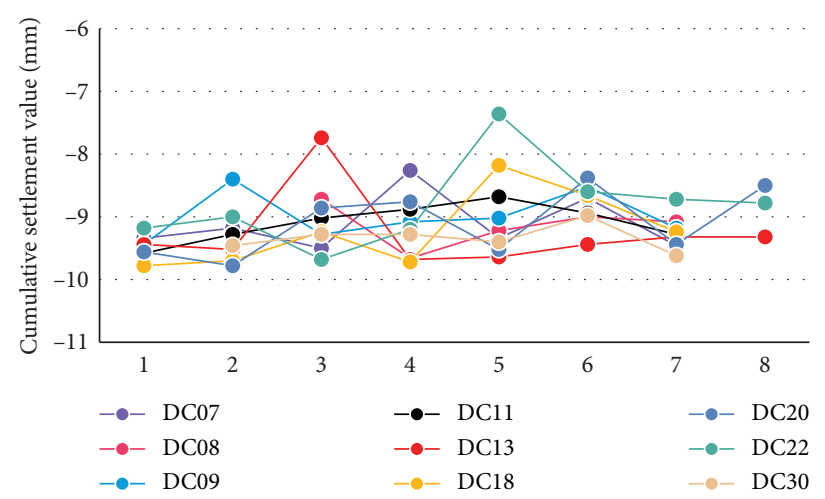

FiguRE 12: Variation curve of lateral displacement of monitored sections at Junfeng Road Station.

TABLE 10: Statistics of surface settlement data.

\begin{tabular}{lcccc}
\hline Scope & $0 \sim 10 \mathrm{~mm}$ & $-10 \sim 0 \mathrm{~mm}$ & $-20 \sim-10 \mathrm{~mm}$ & $-30 \sim-20 \mathrm{~mm}$ \\
\hline Number & 2 & 68 & 1 & 1 \\
Frequency & 0.03 & 0.94 & 0.01 & 0.01 \\
Cumulative frequency & 0.03 & 0.97 & 0.99 & 1.00 \\
\hline
\end{tabular}

the structure itself and the surrounding environment is much smaller than that during the excavation stage. Therefore, this study on the cumulative settlement control index mainly focuses on the surface cumulative settlement control value after the excavation.

According to the principle of basic consistency of tunnel burial depth, geological conditions, and surrounding environment, this group selected a total of 72 effective surface settlement measurement points of Wannianquan Road Station and Junfeng Road Station. Statistical analysis was carried out on 72 effective measuring points, among which the maximum settlement value was $-23.26 \mathrm{~mm}$, the minimum settlement value was $2.21 \mathrm{~mm}$, and the mean value was $-8.66 \mathrm{~mm}$. The specific values are listed in Table 10, and the frequency distribution is drawn as shown in Figures 13 and 14.

As can be seen from Table 9 and Figures 13 and 14, the final value of surface settlement is mainly below $-10.00 \mathrm{~mm}$, accounting for $97 \%$. According to the actual monitoring data, the final surface settlement value of Wannianquan Road Station and Junfeng Road Station is basically between -8 and $-10 \mathrm{~mm}$, accounting for $85 \%$ of the total. There are only two cases of

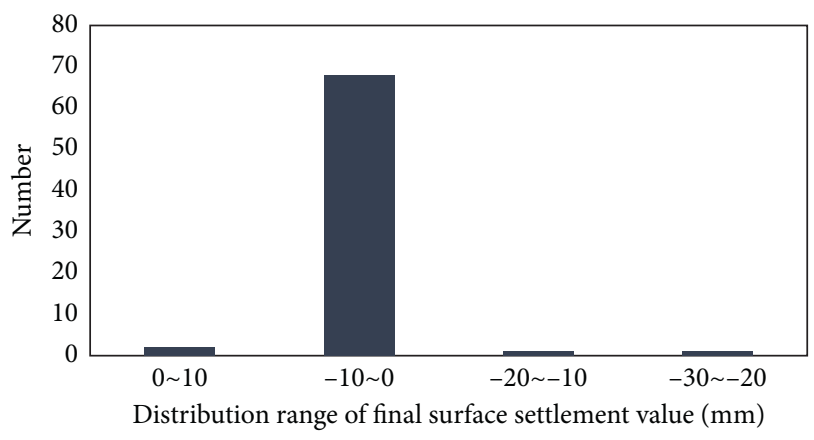

FIgURE 13: Histogram of final value distribution of surface settlement.

points over $-10.00 \mathrm{~mm}$, which belong to small probability events, so it should be analyzed specifically for this measuring point. So, when the station arch above conditions of surrounding rock is good, above the earth surface accumulated settlement is small, according to the specification and design documents control standard $30.00 \mathrm{~mm}$ can satisfy the actual needs. 


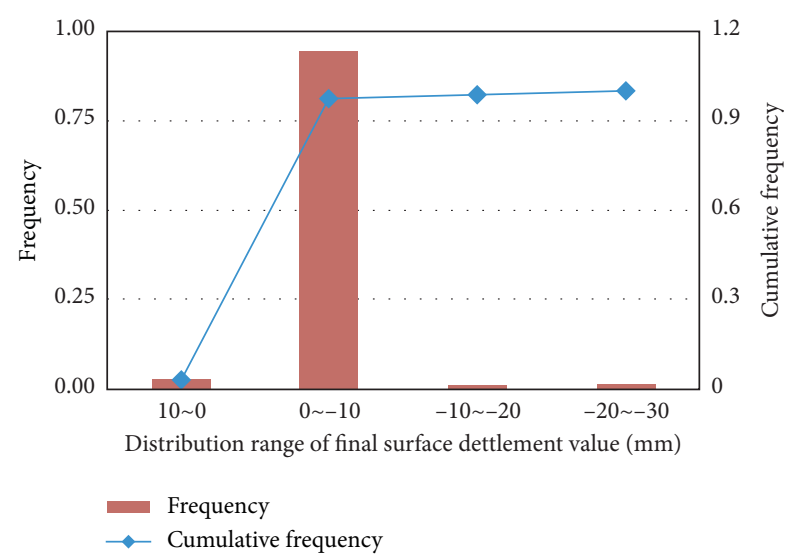

FIgURE 14: Histogram of frequency distribution of final surface settlement values.

\section{Conclusion}

(1) According to the change curve of the whole process of the ground surface settlement of each station, the general change law of the ground surface settlement in the excavation process of the station is roughly consistent. Surface settlement will be caused when both sides of the tunnel are excavated, but the general settlement is relatively small. Large surface settlement will occur during the middle or middle guide hole excavation. The change of surface settlement caused by excavation of soil and construction of station structure is not significant.

(2) Through curve fitting, it is found that the effect of using unary cubic polynomial is better, and the correlation coefficient is basically above 0.95 . However, it can also be seen that the formula coefficients obtained by fitting the surface settlement change curves of each station are quite different, which indicates that the surface settlement change curve in the excavation process of long-span underground tunnel is actually greatly affected by various factors.

(3) The variation of station surface lateral displacement is influenced by the tunnel depth, geological conditions, management level of monitoring unit, monitoring layout and monitoring accuracy, and so on, and the overall difference of surface lateral displacement deformation is large. The Wannianquan Road Station basically conforms to Peck surface settlement trough. The surface subsidence of Junfeng Road Station belongs to the overall settlement, and there is no obvious difference in the corresponding area directly above the station, so only the final settlement needs to be controlled.

(4) Based on statistical method, the arch of the surrounding rock conditions is good, the total depth under the condition no more than $10 \mathrm{~m}$, above the earth surface cumulative settlement is small, largespan underground tunnel surface settlement control standard $30.00 \mathrm{~mm}$ is completely reliable

\section{Data Availability}

The experimental data used to support the findings of this study are available upon request.

\section{Conflicts of Interest}

The authors declare that there are no conflicts of interest regarding the publication of this paper.

\section{Acknowledgments}

This work was supported by the National Natural Science Foundation of China (51708316; 51778312), the China Postdoctoral Science Foundation Funding (2018M632641); the Shandong Key Research and Development Program (2017GSF16107; 2018GSF11700), the Shandong Provincial Postdoctoral Innovation Program of China (201903043), the Higher Educational Science and Technology Program of Shandong Province (J16LG02), and the Qingdao Postdoctoral Applied Research Program (2018101).

\section{References}

[1] R. N. Colvile, S. Kaur, R. Britter et al., "Sustainable development of urban transport systems and human exposure to air pollution," Science of The Total Environment, vol. 334-335, no. 1, pp. 481-487, 2004.

[2] M. Jakimavičius, "Multi-criteria assessment of urban areas transport systems development according to sustainability," IEEE Transactions on Education, vol. 56, no. 1, pp. 9-17, 2013.

[3] X. Bai, M. Zhang, T. Liu, and N. Yan, "Measurement analysis of ground settlement induced by shallow metro station constructions in rock-soil combination strata," Electronic Journal of Geotechnical Engineering, vol. 19, no. Z3, pp. 10719-10730, 2014.

[4] P. B. Attewell, J. Yeates, and A. R. Selby, Soil Movements Induced by Tunnelling and Their Effects on Pipelines and structures, OSTI, Monterey, USA, 1986.

[5] R. B. Peck, "Deep excavations and tunneling in soft ground," in Proceedings of the 7th International Conference on Soil Mechanics and Foundation Engineering, pp. 225-290, Mexico City, USA, March 1969.

[6] Y. S. Fang, S. J. Lin, and J. S. Lin, "Time and settlement in EPB shield tunnelling[J]," Tunnels and Tunnelling, vol. 25, no. 11, pp. 27-28, 1993.

[7] C. W. W. Ng, G. B. Liu, and Q. Li, "Investigation of the longterm tunnel settlement mechanisms of the first metro line in Shanghai," Canadian Geotechnical Journal, vol. 50, no. 6, pp. 674-684, 2013.

[8] H. Mohamad, P. J. Bennett, K. Soga, R. J. Mair, and K. Bowers, "Behaviour of an old masonry tunnel due to tunnelling-induced ground settlement," Géotechnique, vol. 60, no. 12, pp. 927-938, 2010.

[9] A. Özbek, S. Türkmen, and M. Gül, "The deformation evaluation of Kızlaç T3A Tunnel (Osmaniye, Turkey)," Engineering Geology, vol. 67, no. 3-4, pp. 309-320, 2003.

[10] O. Ibrahim, "Interaction of longitudinal surface settlements for twin tunnels in shallow and soft soils: the case of Istanbul Metro," Environmental Earth Sciences, vol. 69, 2013.

[11] P. Yan, Z. Zhao, W. Lu, Y. Fan, X. Chen, and Z. Shan, "Mitigation of rock burst events by blasting techniques during 
deep-tunnel excavation," Engineering Geology, vol. 188, pp. 126-136, 2015.

[12] C. Y. Ou, R. N. Hwang, and W. J. Lai, "Surface settlement during shield tunnelling at $\mathrm{CH} 218$ in Taipei," Canadian Geotechnical Journal, vol. 35, no. 1, pp. 159-168, 2011.

[13] G. Zhang, Z. Du, and J. Song, "Construction settlement monitoring analysis and control countermeasures of metro station arch cover method," Journal of Rock Mechanics and Engineering, vol. 31, no. S1, pp. 3413-3420, 2013.

[14] B. Li, X. Li, and G. Xu, "Research and application of copper/ steel composite materials," Materials Guide, vol. 02, pp. 2224, 2002.

[15] M. Sharifzadeh, F. Kolivand, M. Ghorbani, and S. Yasrobi, "Design of sequential excavation method for large span urban tunnels in soft ground-niayesh tunnel," Tunnelling and Underground Space Technology, vol. 35, pp. 178-188, 2013.

[16] Ministry of Housing and Urban-Rural Development, Technical Specifications for Urban Rail Transit Project Monitoring, China Building Industry Press, Beijing, China, 2013.

[17] E. Tryggvason, "Measurement of surface deformation in Iceland by precision leveling," Journal of Geophysical Research, vol. 73, no. 22, pp. 7039-7050, 1968.

[18] S. A. Kinnas, Boundary Element Method (BEM), Springer, Berlin, Germany, 1999.

[19] T. Touhei, T. Hinago, and Y. Fukushiro, "Inverse scattering analysis of elastic half space by means of the fast volume integral equation method," Engineering Analysis with Boundary Elements, vol. 44, 2013.

[20] X. Li, P. Wang, and J. Zhang, "Calculation and analysis of ground subsidence and deformation around soft soil foundation pit," Rock and Soil Mechanics, vol. 09, pp. 1879-1882, 2007.

[21] W. Fang, S. He, L. Jun, and R. L. Cao, "Analysis of control standard for ground surface settlement in excavating metro station by shield tunnel combined with pile-beam-arch method," Rock and Soil Mechanics, vol. 33, pp. 289-296, 2012.

[22] J. Yorita, M. Okamura, K. Ishigaki, and T. Asakura, "Deformation properties of quaternary cohesive soil in response to tunneling and examination about influence of cracks," Journal of the Japan Society of Engineering Geology, vol. 49, no. 4, pp. 236-245, 2011. 